\title{
Dental Restorations of Co-Cr Using Direct Metal Laser Sintering Process
}

\author{
Diana-Irinel Băilă
}

\begin{abstract}
In this paper are presented Additive Manufacturing process that can be used to manufacture dental restorations, like bridges, crowns, chapels. Materials used for these innovative processing methods are very different from diverse liquid photopolymers, metal powders, polyamide powders, ceramic powders or different materials in solid state. Dental restorations should be made of stainless steel material to provide mechanical strength and good corrosion. It must also present a degree of cleaning similarly to that glass and allow to be sterilized in good conditions.
\end{abstract}

Index Terms-Direct metal laser sintering, dental bridge, dental implant, Co-Cr powders.

\section{INTRODUCTION}

The main objective of this paper is to determine the Additive Manufacturing processes that may be used for processing dental restorations, respectively for various medical implants, also was studied different metallic materials used for medical instruments manufacturing.

Technologies known as the Additive Manufacturing consist of building a physical model, a prototype or final piece, starting from a $3 \mathrm{D}$ model obtain using a CAD program by a industrial or medical scan [1]-[3].

Additive Manufacturing Processes is assigned to these new technologies that begin to grow in importance due to manufacturers to reduce conception times to product launch on the market and the cost for the assimilation of new products and to manufacture parts difficult or impossible to fabricate by other methods.

Characteristic of all these technologies is their ability to perform complex three-dimensional objects, starting from a CAD description without using conventional machine tools or specific devices. The pieces are quantified through a succession of sections and built using iterative process of building a piece section by section.

All Additive Manufacturing technologies follow the same basic steps, namely:

Manuscript received October 22, 2016; revised April 3, 2017. This work has been funded by University POLITEHNICA of Bucharest, through the "Excellence Research Grants" Program, UPB - GEX. Identifier: UPB-EXCELENT,Ă-2016 Research project title "Experimental researches concerning new biocompatible materials manufacturing by DMLS process used for personalized dental implants and restorations / Cercetări experimentale privind utilizarea de noi materiale biocompatibile destinate implanturilor şi restaurărilor dentare personalizate fabricate prin sinterizare DMLS", Contract number 29/26.09.2016.

Diana-Irinel Băilă is with the University Politehnica of Bucharest, Blv. Splaiul Independentei, 313, Sector 6, cod 060042, Romania (e-mail: baila_d@yahoo.com).
1. Obtaining CAD model that includes full description of the piece, using a CAD program, an industrial scanning system, a CT or an RMN.

2. Transfer to processor sectioning CAD model. Slicing can be done, in many cases, the CAD software used for modelling. The most common method is an approximation model with flat triangular elements.

3. Triangular model is so prepared for sectioning and construction.

4. The construction part is done in specific mode of each process and the settlement patterns is specific to each process.

5. Cleaning and finishing operations are necessary for supports removed used in construction or for removed material excess and seeks to improve the dimensional accuracy and quality of pieces.

Additive Manufacturing processes they differ by:

-material used and under what form is used;

-how will be supported the model during the construction;

-how will be added a new layer;

-how new layer will be added compared to the previous one;

-how will mark the outlines for each section;

-how will mark the area between the inner and outer contour of a section.

Some of the most promising processes are those that are made up fabricated metal powders known as DMLS (Direct Metal Laser Sintering), EOS (Electron Beam Melting), SLM (Selective Laser Melting), LC (Laser Consolidation) and LENS (Laser Engineering Net Shaping) [1]-[3].

The materials used for medical instruments manufacturing must be stainless steel material to provide mechanical strength, good corrosion and for implants must to be biocompatible materials [4]-[8].

The most used metalic materials used for DMLS manufacturing are Ti6Al4V, Ti-Ni alloys, stainless steel 304 or 316L, and Co-Cr alloys [9]-[13].

\section{EXPERIMENTAL RESEARCH}

Direct metal laser sintering (DMLS) is an additive metal fabrication technology, occasionally referred to as selective laser sintering (SLS) or selective laser melting (SLM).

This process utilizes a 3 -dimensional CAD model, creating a file which is then forwarded to the software utilized by the machine.

The direct metal laser sintering machine makes use of a powerful fibber optic laser. Within the build chamber is a platform for material dispensation and a build platform, in addition to a recoated blade which moves new powder on top of the build platform. 
With a focused laser beam, this DMLS technology melts metal powder locally to fuse it into solid parts. Parts are constructed additively, one layer at a time [2].

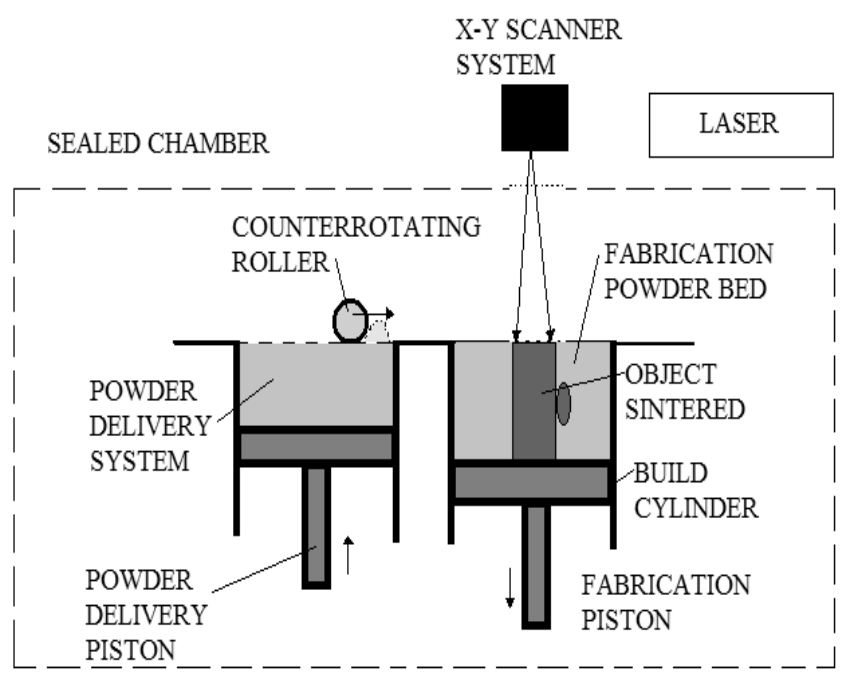

Fig. 1. Direct Metal Laser Sintering process [2].

Using the DMLS process, metal parts of the most complex geometries are built layer-by-layer (down to 20 microns) directly from 3D CAD data.

Parts built using DMLS have excellent mechanical properties equivalent to wrought materials, high detail resolution, and exceptional surface quality. The metal powder is melted entirely to create a fully dense, fine, homogenous structure. Unique geometric freedom of design enables DMLS to form cavities and undercuts, which with conventional machining methods, can only be produced with great difficulty, if at all.

The process is completely automated and is usually completed within just a few hours. DMLS is a net-shape process, accurately creating parts that yield, high resolution, great surface quality and excellent mechanical properties.

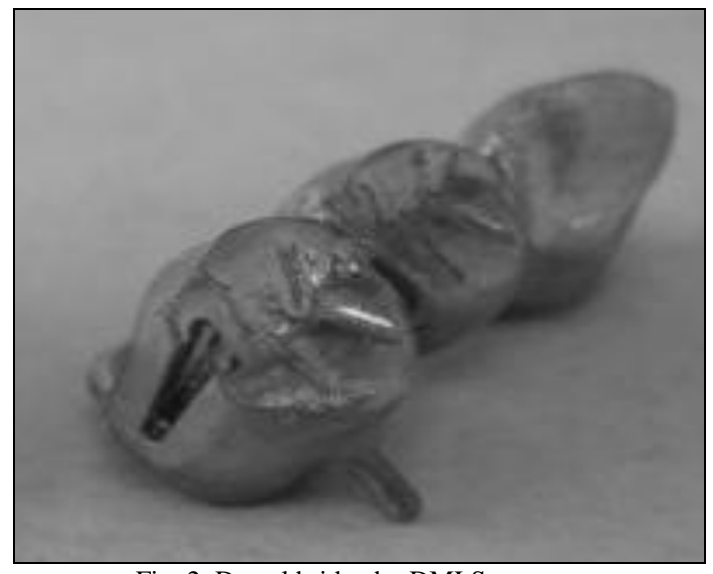

Fig. 2. Dental bridge by DMLS process.

Additionally, when a part needs to be tested and re-designed over and over, the lead time for receiving a traditionally tooled part can create a large bottleneck in the final production process. DMLS produces parts that are extremely high quality and can be built in a matter of hours or days rather than weeks.

The ability to generate functional metal prototypes in short order radically impacts design processes, accelerating design cycles and time to market.

In this work were obtained a dental bridge (Fig. 2) and a dental crown (Fig. 3) using Co-Cr powders (ST2724G) manufactured by direct metal laser sintering (DMLS) process.

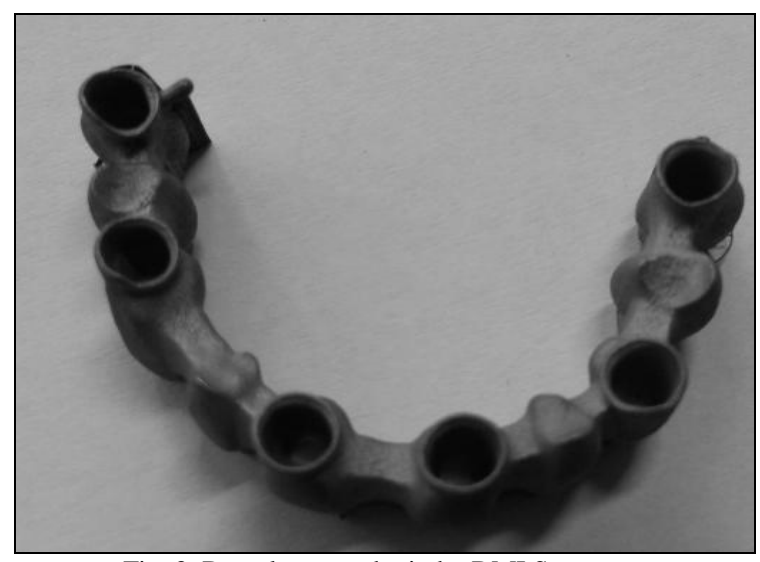

Fig. 3. Dental crown obtain by DMLS process.

Chemical composition of Co-Cr alloy is $54.31 \% \mathrm{Co}$; $23.08 \% \mathrm{Cr} ; 11.12 \% \mathrm{Mo} ; 7.85 \% \mathrm{~W}, 3.35 \% \mathrm{Si}$ and $\mathrm{Mn}, \mathrm{Fe}<0.1$. In the Table I is presented main mechanical properties of $\mathrm{Co}-\mathrm{Cr}$ alloy powder used in preparation of compacts [3].

TABLE I: Mechanical Properties [3]

\begin{tabular}{lc}
\hline \hline Engineering Property & Values \\
\hline Elastic limit 0,2\% (Rp0,2) & $815 \mathrm{MPa}$ \\
Elongation at break & $10 \%$ \\
Vickers hardness & $375 \mathrm{HV} 5$ \\
Elastic module & $229 \mathrm{GPa}$ \\
Volume mass & $8,336 \mathrm{~g} . \mathrm{cm}^{-3}$ \\
Corrosion resistance & $<4 \mu \mathrm{g} / \mathrm{cm}^{2}$ \\
Thermal expansion coefficient & $14,5^{*} 10^{-6} \mathrm{~K}^{-1}$ \\
\hline \hline
\end{tabular}

The Co-Cr powder has a fine granulation with grain size around $20 \mu \mathrm{m}$ and spherical grains morphology. In the SEM images the great particles represent Co grains and the smaller particles represent $\mathrm{Cr}$ grains (Fig. 4).

The dental crown are sintered using Phenix Systems machine type PXS \& PXM Dental, having the fibber laser $(P=50 W, \lambda=1070 \mathrm{~nm})$, the manufactured volume is $100 \times 100 \times 80 \mathrm{~mm}$, dimensions of machine are $L=1.20 \mathrm{~m} ; l=$ $0.77 \mathrm{~m} ; H=1.95 \mathrm{~m}$. The soft used is Phenix Dental. The temperature of sintering process is $1300^{\circ} \mathrm{C}$. For the sintering process is used nitrogen gas.

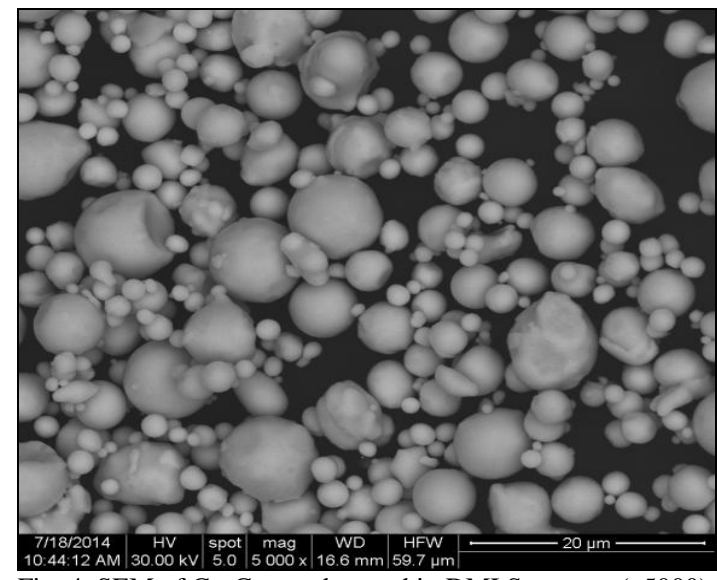

Fig. 4. SEM of Co-Cr powder used in DMLS process (x5000). 
The dental crown are sintered using Phenix Systems machine type PXS \& PXM Dental, having the fibber laser $(P=50 \mathrm{~W}, \lambda=1070 \mathrm{~nm})$, the manufactured volume is $100 \times 100$ $\times 80 \mathrm{~mm}$, dimensions of machine are $L=1.20 \mathrm{~m} ; l=0.77 \mathrm{~m}$; $H=1.95 \mathrm{~m}$. The soft used is Phenix Dental. The temperature of sintering process is $1300^{\circ} \mathrm{C}$. For the sintering process is used nitrogen gas.

The morphology and semi-quantitative analysis of powder and sintered pieces (dental crowns) were performed using scanning electron microscope QUANTA INSPECT F.

The chemical compositions of the samples studied were used out images of secondary electrons and backscatter electron images.

XRD analysis was performed using an X-ray diffractometer that uses PAnalytical Empyrial characteristic $\mathrm{CuK} \alpha$ radiation and wavelength 1.541874. Spectrum acquisition was performed in Bragg-Brentano geometry.

\section{RESULTS AND DISCUSSIONS}

The DMLS process involves use of a 3D CAD model of type "stl". This file is created and sent to the machine's software.

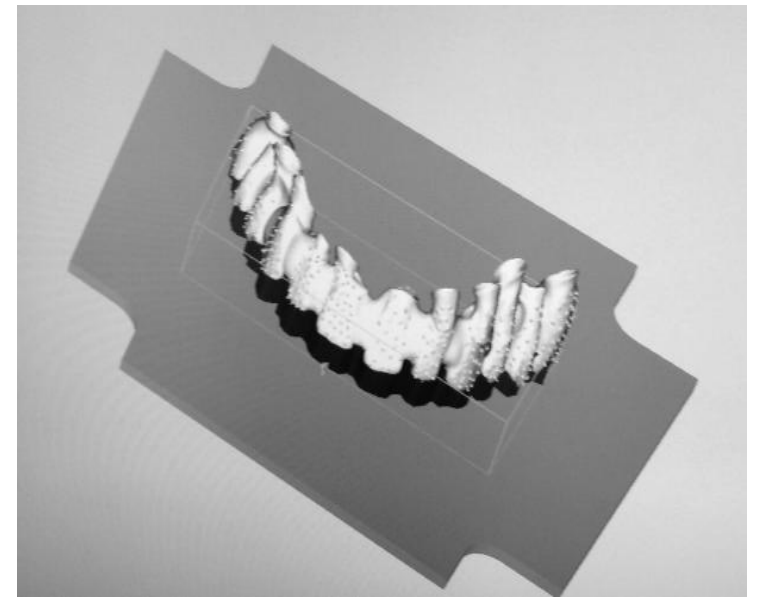

Fig. 5. "stl" file of the dental crown.

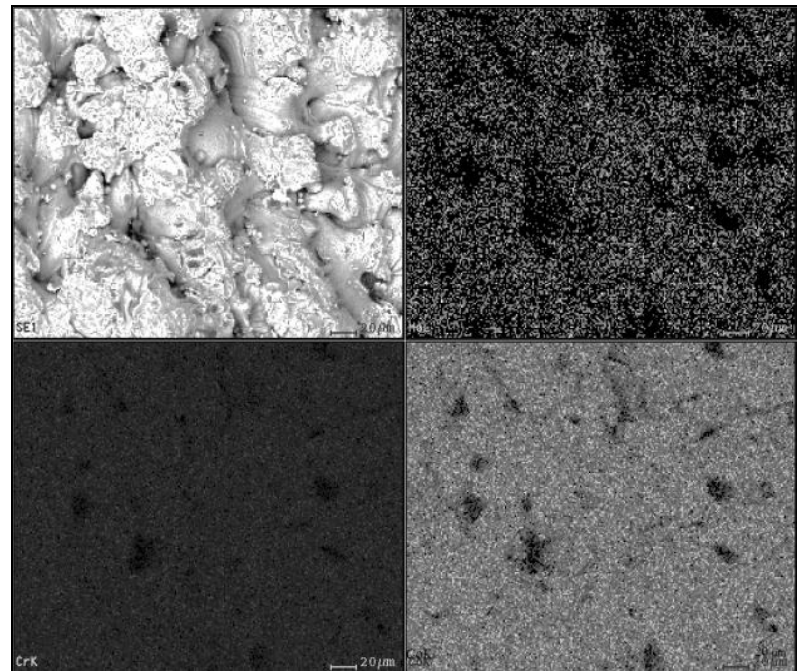

Fig. 6. Mapping of Co-Cr sintered by DMLS process (x5000).

In Fig. 5 is presented the content of the "stl" file for a dental crown to obtain by sintering process DMLS, using the program Phenix System.
The sintering temperature varied between $1300^{\circ} \mathrm{C}-$ $1600^{\circ} \mathrm{C}$ for dental crown manufactured by DMLS process. The mapping of the Co-Cr alloy sintered by DMLS process is presented in Fig. 6.

In Fig. 7 is presented the DMLS machine, Phenix Systems machine type PXS \& PXM Dental.

The CAD/CAM software of Phenix Dental machine presents automatic generation of products supports, creation of manufacturing files, positioning of 3D models on the manufacturing plate, etc.

The main advantages of this machine are: reduction of unit production cost, easy to use, optimal mechanical features.

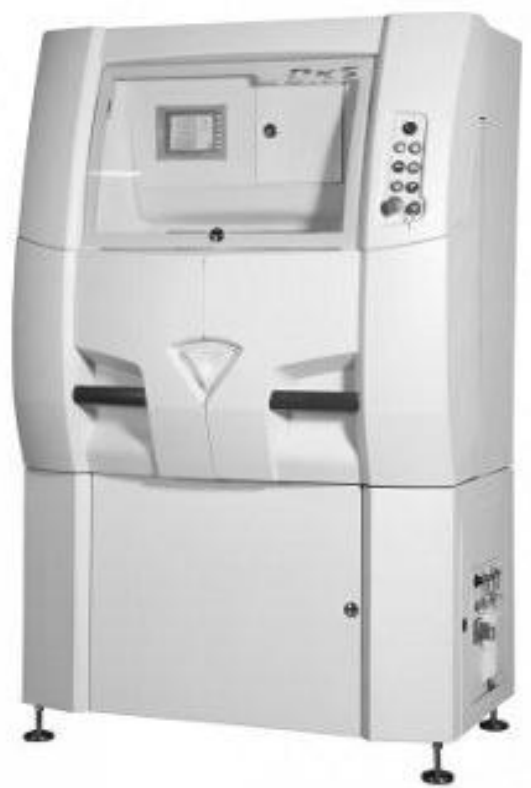

Fig. 7. DMLS machine, Phenix Systems machine type PXS \& PXM Dental [3].

The dental crown obtain by sintering DMLS process from Co-Cr powders presents a good mechanical resistance better that another materials who are used in dentistry like $\mathrm{Ni}-\mathrm{Cr}$ alloys.

The dental crown was realized with some little protuberances necessary to permit a better assembly with the ceramic teeth.

EDS analysis remark the presence of $\mathrm{Co}$ and $\mathrm{Cr}$ as majority mass and other elements like: Mo, Si, Mn, Fe, W as traces.

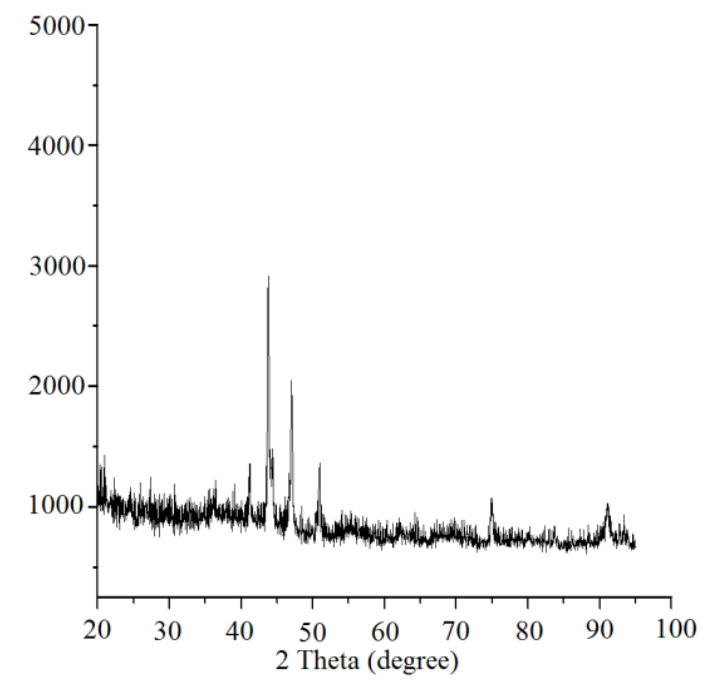


Fig. 8. XRD analysis of Co-Cr alloy.

The chemical composition was determinated by XRD and the result evidenced the chromium cobalt molybdenum with chemical formula: $\mathrm{Cr}_{0.32} \mathrm{Mo}_{0.04} \mathrm{Co}_{0.64}$ according with ASTM 04-016-6870, like in Fig. 8.

\section{Dental ImPlants ManUfactured By DMLS PROCESS}

There were realized many tests concerning the dental implants of Ti4 powder, using the DMLS process, for a real case of a patient, that needed 3 dental implants for positions D37, D46, D47.

For the implantable operation of Ti4 dental implants it was realized a dental panoramic view of the patient skull/mouth, like in Fig. 9.

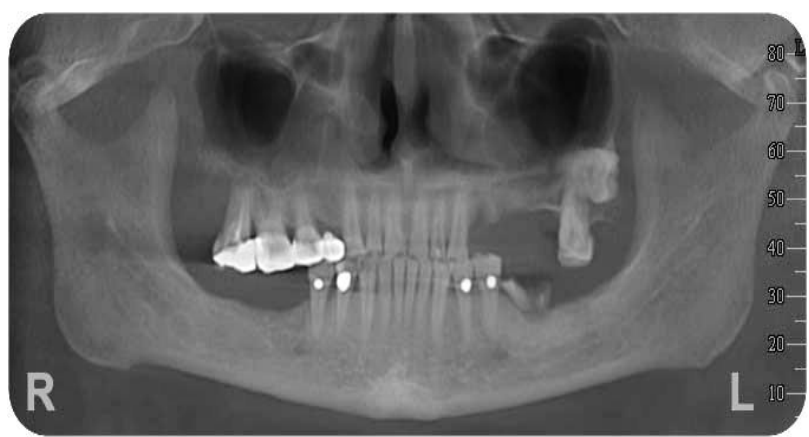

Fig. 9. Dental panoramic view of the patient.

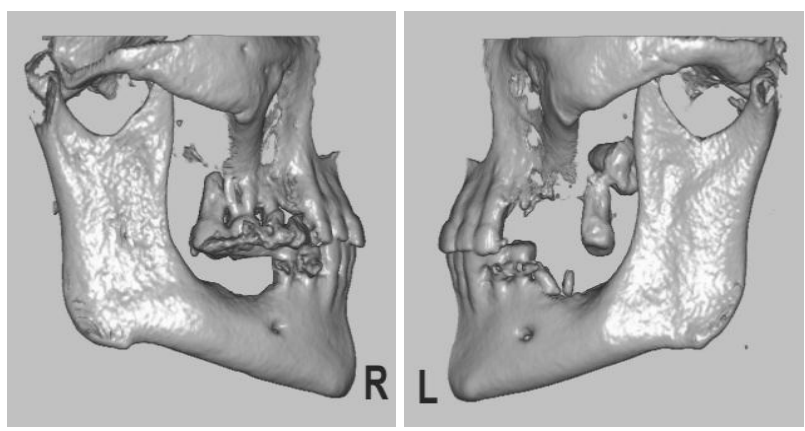

Fig. 10. 3D images for the left and right part of dental panoramic view.

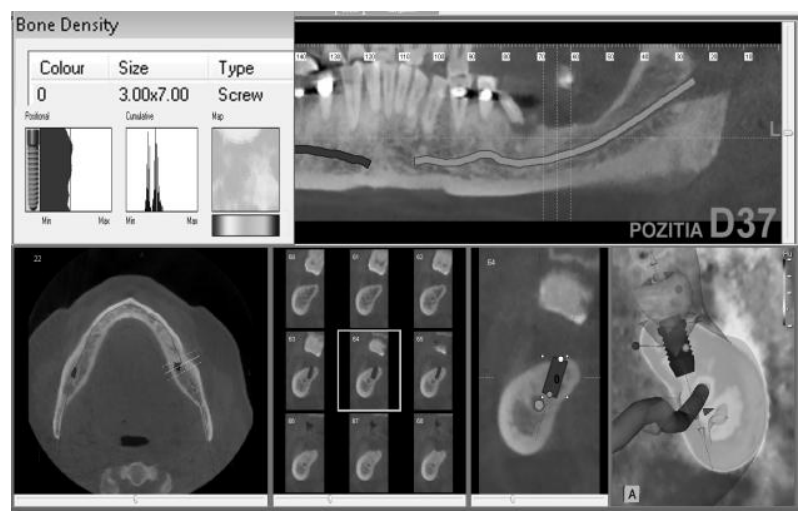

Fig. 11. Dental implant simulation for position D37-left.

In Fig. 10 are presented 3D images or the left and right part of dental panoramic view for the patient necessary for implantology of personalized dental implants.

In Figs. 11, 12, 13 there are presented the implants simulations for positions D37-left, D46-right and D47-right.

It can be observed that the images also evidentiate the bone density for all the positions, the colors distribution is a good advice for the doctor to take a decision if a certain area/position can be fitted with an implant.

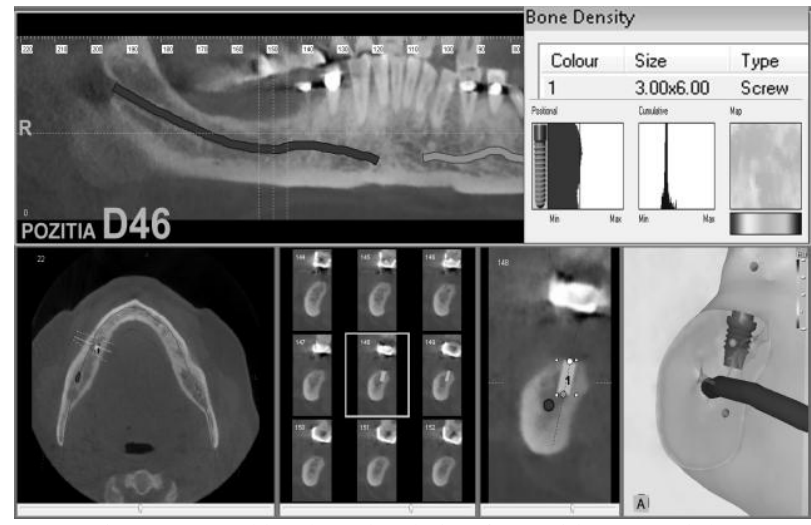

Fig. 12. Dental implant simulation for position D46-right.

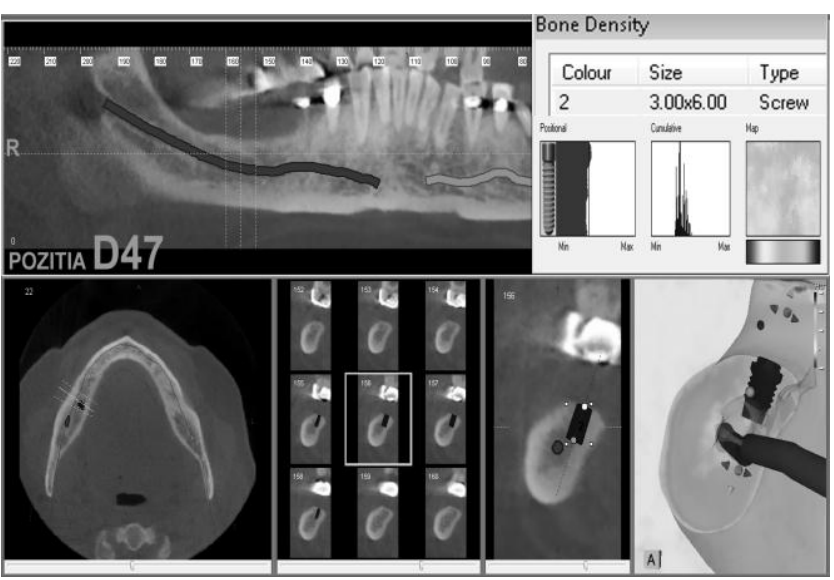

Fig. 13. Dental implant simulation for position D47-right.

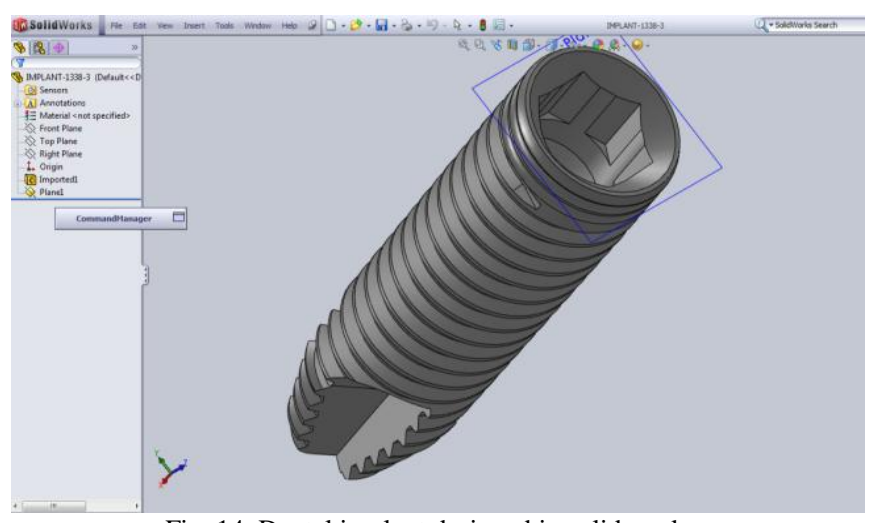

Fig. 14. Dental implant designed in solid works.

In Fig. 14 is presented the dental implant designed in Solid Works software and saved as a ,stl“ file. This file is used by the Phenix Systems software machine to permit the dental implant manufacturing. In Fig. 15 is presented the cilindrical dental implant of Ti4 alloy manufactured by DMLS.

Dental alloy powder of pure titanium Ti4 (grade 4) is used for the production of dental prostheses in the Laser Melting, respectively, Laser Sintering Technology. This material present a very good biocompatibility, high strength and a wide spectrum of indications [14], [15]

It is appropriate for the production of pliers, crowns and bridges, as well as partial denture works. Starbond Ti4 Powder is suitable for the processing in the systems HintELs rapidPro* SLM 50, SLM 100* and for 
Phenix Systems machines.

The chemical composition is $\mathrm{Ti}>99 \%$ and other ingredients $<1 \%\left(\mathrm{~N}, \mathrm{C}, \mathrm{H}, \mathrm{Fe}, \mathrm{O}_{2}\right)$.

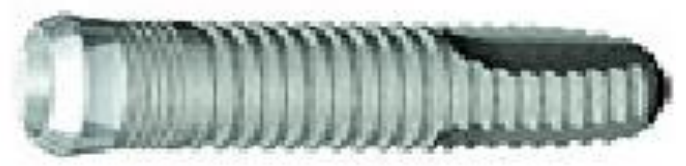

Fig. 15. Sample of a cylindrical dental implant of Ti4 alloy manufactured by DMLS.

Granulometry of the alloy powder is between $10-45 \mu \mathrm{m}$. [14], [15].

In Table II are presented the principal mechanical properties of $\mathrm{Ti} 4$ powder used in DMLS manufacturing process.

TABLE II: MECHANICAL PROPERTIES [15]

\begin{tabular}{lc}
\hline \hline Mechanical Property & Values \\
\hline Proof stress & $532 \mathrm{MPa}$ \\
Ultimate tensile strength & $657 \mathrm{MPa}$ \\
Tensile elongation & $4 \%$ \\
Density & $8,8 \mathrm{~g} / \mathrm{cm}^{3}$ \\
Thermal expansion coefficient & $14 \mu \mathrm{m} / \mathrm{m}^{\circ} \mathrm{C}$ \\
Solidus Liquidus interval & $1305-1400{ }^{\circ} \mathrm{C}$ \\
\hline \hline
\end{tabular}

\section{CONCLUSIONS}

The Direct Metal Laser Sintering technology permits manufacturing the unique complex prototypes in the medical domain. Co-Cr alloy powder has good sintering properties grace of spherical grain form and of fine size of grain of 20 $\mu \mathrm{m}$. The low granulometry of powder permit a better control of the thermal gradient during the contact between the material and the laser.

For dental restorations manufacturing, the advantages obtained using Co-Cr alloy powder are: an excellent material quality and surface status limited mechanical stress within the part being produced; increased definition of the details; reduction in size of production supports. The sintered material presents porosity in the material obtained and some spherical particles which were not sintered, due to the cleaning process.

DMLS technology permits to manufacture complex geometry prototypes, like different types of dental crowns, bridges or analogue implants. The precision of dental crowns obtained by DMLS is very good, by microns order. The dental crown can be sterilized in good conditions. The dental crown can be used successfully for the patient, present good mechanical resistance, good corrosion resistance and is a tolerable material in medicine.

$3 \mathrm{D}$ printing is revolutionizing global industrial manufacturing, but it's also being adopted to create human tissues. Researchers are dedicated to finding a way to produce desperately needed human organs in the lab, including kidneys, livers and hearts.

\section{REFERENCES}

[1] P. Berce, N. Balc, C. Caizar, R. Pacurar, A. S. Radu, S. Bratean, and I. Fodorean, Additive Manufacturing Technologies and Their Applications, Romanian Academy, Bucharest, 2014.

[2] E. Grenda, Printing the Future, Castle Island's, 2006.

[3] Phenix Systems. [Online]. Available: http://www.phenix-systems.com/en/materials

[4] D. R. Buddy, S. Hoffman, F. Schoen, and J. Lemons, Biomaterials Science, An Introduction to Materials in Medicine, 3rd ed., Academic Press, 2013

[5] F. H. Silver and L. David, Biomaterials Science and Biocompatibility, Springer Verlag, 1999

[6] B. P. Joon and J. D. Bronzi, Biomaterials. Principles and Applications, CRC Press, 1999

[7] W. Schatt and K. P. Wieters, Powder Metallurgy. Processing and Materials EPMA, 1997

[8] I. Vida-Simiti, Technological Properties in Powders Metallurgy, Enciclopedical, Bucharest, 1999

[9] A. F. von Recum Handbook of Biomaterials-Evaluation, 2nd ed., 1999.

[10] H. V. Buf and G. Buşilă, "Technologies and installation for titanium powder manufacturing," in Proc. Third Conference in Powder metallurgy, Cluj-Napoca, pp. 169-174, 1998.

[11] D. I. Băilă, O. C. Mocioiu, C. Zaharia, R. Trusca, A. Surdu, and M. Bunea, Rev. Roum. Chim, vol. 60, no. 9, pp. 921-930, 2015.

[12] D. I. Băilă, "Medical implants realized from the sintered compacts of titan-hydroxyapatite" DAAAM Zadar Croatia, pp. 594-596, 2013.

[13] D. I. Băilă, Biomaterials Used in Additive Manufacturing, Printech, Bucharest, 2016.

[14] C. Rontescu, O. R. Chivu, A. Pacioga, G. Iacobescu, I. M. Vasile, D. T. Cicic, and A. Semenescu, "Research on biocompatible titanium alloys test samples obtained by sintering," Rev. Chim.(Bucharest), vol. 67, no. $6,2016$.

[15] SCHEFTNER 24. [Online]. Available: http://scheftner24.de/index.php/starbond-cos-powders.html

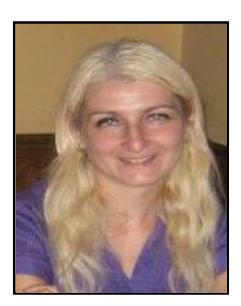

Băilă Diana Irinel is a lecturer in University POLITEHNICA of Bucharest. She holds courses for the following subjects: manufacturing processes, manufacturing equipments.

She got the $\mathrm{Ph} . \mathrm{D}$ in industrial engineering with thesis title "Theoretical and experimental research on the assimilation of new biocompatible materials processed by RP (rapid prototyping) technology" from Technical University of Cluj-Napoca, The Faculty of Machine Building in 2009. She is a member in 7 research contracts. Her 10 papers have been published in ISI journals with impact factor. 